\title{
O Choque da Mulher Risky(Qué1): A feminilidade e o trauma na era da Primeira Guerra Mundial na dança de Maud Allan e Anna Pavlov ${ }^{23}$
}

\author{
Victoria Thoms ${ }^{4}$ \\ Centre for Dance Research/C-DaRE, Coventry University, Coventry/UK \\ E-mail: ac1420@coventry.ac.uk \\ Tradução de Márcia Donadel \\ E-mail: mdonadel@gmail.com
}

\section{Resumo}

Qual foi o papel da figura da dançarina feminina na negociação das ansiedades culturais na era da Primeira Guerra Mundial? Eu exploro essa questão analisando a performer Maud Allan, famosa por suas interpretações dançadas de Salomé na Londres do pré-guerra e a causa de um extraordinário processo por difamação em 1918, que une sexualidade feminina desviante e espionagem em tempos de guerra. Justaponho Allan com a bailarina Anna Pavlova, sua contemporânea, modelo por excelência de uma feminilidade adequada. Esses dois exemplos oferecem uma rica comparação a partir da qual podemos discutir como a dança e a feminilidade foram as bases para incitar e atenuar o profundo trauma cultural da era da Primeira Guerra Mundial.
What role did the figure of the dancing female play in negotiating cultural anxieties in the Great War era? I explore this question by looking at the female performer Maud Allan who was famous for her danced interpretations of Salomé in pre-War London and cause of a sensational libel suit in 1918 bring together deviant female sexuality and wartime espionage. I juxtapose Allan with ballerina Anna Pavlova, a contemporary, and role model par excellence for proper femininity. These two examples offer a rich comparison from which to discuss how dancing and femininity was the grounds for inciting and palliating the profound cultural trauma of the Great War era. 
Figura 1-Imagem recortada de "Slaying Militarism with the Pen" The Sketch, 6 de janeiro de 1915.

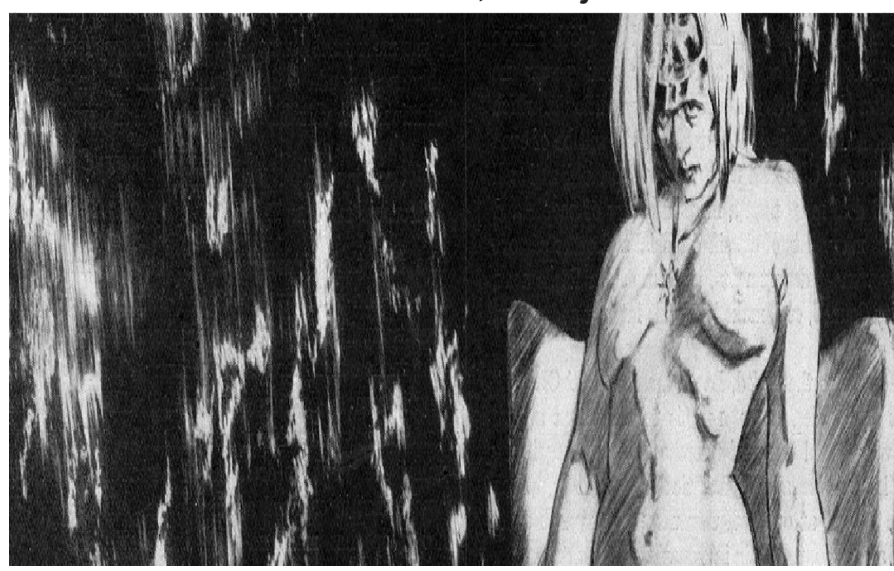

Fonte: (C) Illustrated London News Ltd / Mary Evans. Todos os direitos reservados.

Qual o papel da figura da dançarina feminina na negociação das ansiedades culturais da era da Primeira Guerra Mundial? Como essas ansiedades

1 Risky: perigosa, arriscada; risque: apagada, excluída; risqué (vocábulo emprestado do francês): ousada. N. da T.

2 Eu me sinto grata pela oportunidade de ter apresentado os primeiros pensamentos sobre esse tema no Research Café organizado por Juliet Simpson na Faculty of Arts and Humanities, Coventry University em março de 2016 e na conferência Pack UpYour Troubles: Performance Cultures in the First World War, organizada pela Kent University em abril de 2015 como parte do AHRC, co-financiado pelo projeto de financiamento público Gateways to the First World War. Eu gostaria de agradecer também à Luci Gosling da Mary Evans Picture Library pelo seu conhecimento e orientação na pesquisa das imagens apresentadas e aos funcionários da British Library Newspaper Collection e das coleções do Victoria and Albert Theatre and Performance na Bly the House, que também prestaram enorme ajuda.

3 Este texto foi publicado originialmente em inglês em 2018 no livro "A World of Muscle, Bone \& Organs: Research and Scholarship in Dance " e está disponível online no link: https://www.coventry.ac.uk/research/about-us/ researchnews/2018/c-dare-e-book/. A tradução em português foi elaborada pela Dra. Márcia Donadel. A forma de distribuição das citações e numeração das figuras foram reelaboradas para adequar-se às diretrizes da Revista Cena, porém seu conteúdo foi mantido conforme o original.

4 Victoria Thoms é uma pesquisadora em dança interessada em debates práticos e teóricos que reunem a performance, o trauma e os estudos de gênero. Ela é autora de livro Martha Graham (2013) e é membra do comitê executivo da Sociedade para Pesquisa em dança do Reino Unido. podem estar relacionadas às preocupações dessa era com as ideias tradicionais e hegemônicas sobre feminilidade e masculinidade? Por fim, como podemos entender o trauma endêmico do início do século XX como um sintoma dessa problemática de gênero? Nesse texto, abro uma discussão sobre trauma cultural como decorrente de ansiedades em torno da feminilidade e da identidade tendo como pano de fundo a Primeira Guerra Mundial, profundamente influenciado pela convulsão social e pela perda devastadora de vidas devido ao conflito. Eu exploro essas ansiedades analisando a performer Maud Allan, famosa por sua interpretação dançada repleta de erotismo da infame personagem Salomé de Oscar Wilde, na Londres pré-guerra, e que foi a causa de um extraordinário processo por difamação em 1918, reunindo sexualidade feminina desviante e espionagem em tempo de guerra. Para teorizar os efeitos da suposta aberração de Allan, eu a justaponho com a bailarina Anna Pavlova, cuja imagem impecável e prolíficas turnês internacionais a tornaram respeitada e um modelo de feminilidade adequada. Sua morte prematura de pneumonia em 1931 provocou uma expressão internacional de luto sem precedentes. Esses dois exemplos oferecem uma rica comparação a partir da qual pode-se discutir como gênero e identidade feminina, em particular, podem ser lidos como raiz de uma crise cultural significativa. Uma crise cultural ligada aos traumas arraigados nos acontecimentos socioculturais do início do século $X X$, incluindo não apenas a própria Primeira Guerra, mas também a Revolução Russa e o movimento sufragista. Por meio desses exemplos, argumento que o gênero é uma forma impressionante do que chamo de "constelação de trauma", que deixou uma marca indelével naqueles que sobreviveram à conflagração da Primeira Guerra.

Allan e Pavlova não são frequentemente comparadas de forma direta ou mesmo consideradas pares. O legado de Allan é uma nota de rodapé na história eduardiana (MCDEARMON, 1987). Pavlova, por outro lado, experimentou um status continuado de mito como uma das maiores bailarinas de todos 
os tempos (FISHER, 2012). Allan e Pavlova tiveram inícios semelhantes em suas carreiras na dança em Londres. Ambas tiveram suas estreias em Londres no Palace Theatre, um teatro de variedades, com dois anos de diferença. Allan estreou em 1908, Pavlova em 1910. Pavlova, na verdade, escolheu o Palace por causa de sua associação com Allan (MONEY, 1982) e foi muito influenciada pelo estilo marcado por Allan ao montar seus primeiros espetáculos (PRITCHARD, 2013). É bastante provável que Allan também teria prestado atenção às performances de Pavlova.

Esse vínculo configura uma convergência singular e importante para duas carreiras que posteriormente divergiriam radicalmente e, talvez, essa conexão não tenha recebido ênfase suficiente. De fato, são as trajetórias históricas bifurcadas de Allan e Pavlova a partir deste ponto de origem e como mediaram diferentes respostas socioculturais aos eventos da Londres do início do século $X X$ que tornam essa proximidade inicial surpreendente e misteriosa. Esse ponto de origem oferece uma discussão temporalmente extensa sobre o trauma cultural associado às ansiedades sobre nação e império por meio da mudança de noções de feminilidade adequada no contexto da dança britânica.

Para preparar a cena, apresento Allan e Pavlova e sugiro que ambas mediaram respostas socioculturais específicas aos eventos dessa época. Não se tratava apenas de como sua identidade feminina era compreendida e dos tipos de efeitos que esse posicionamento manifestava, mas como sua dança desempenhou um papel central nesse processo. Por isso, também dou atenção especial às suas obras de assinatura que se tornaram sinônimos de suas identidades públicas: para Allan, sua obra notória The Vision of Salomé (1906); e para Pavlova, o melancólico The DyingSwan (1905). Ao analisar essas obras, concentro atenção particular no contexto em torno de suas estreias em Londres em 1908 e 1910, respectivamente. Em seguida, exploro o que considero eventos que se somaram na história pública dessas mulheres - o caso de difamação de Allan em 1918 e a morte de Pavlova 23 anos depois, em 1931 - e como esses eventos ilustram a influência que o gênero exerce sobre o trauma cultural. Esses eventos, separados por mais de duas décadas de enormes mudanças, estão reunidos em meu entendimento de como incitaram uma resposta por vezes global, social e coletiva sobre a personalidade da mulher. A dança e a persona pública dessas duas dançarinas icônicas geraram vasto interesse público e levaram à congregação de pessoas - desde as apresentações esgotadas por meses do Palace Theatre até os encontros em massa espontâneos em espaços públicos. Suas danças ultrapassaram os limites de sua subcultura e impactaram populações maiores, servindo como mediadoras poderosas de desejos e ansiedades sociais ${ }^{5}$. Esse efeito é evidente em como a dança de Allan passou a ser entendida nos últimos meses da Primeira Guerra Mundial em Londres, como uma forma de identidade feminina desviante, socialmente destrutiva e até mesmo maligna (PATTERSON, 2017) e como, por sua vez, a dança de Pavlova gradualmente amenizou as feridas da hegemônica masculinidade forjada por essa era através de seu retorno à feminilidade adequada, submissa e controlável.

\section{Protagonismo feminino}

A Londres no período Pré-Primeira Guerra Mundial que Allan e Pavlova encontraram com aproximadamente um ano de diferença, era uma das capitais cosmopolitas mais ricas do mundo. $\mathrm{O}$ império britânico estava no auge de seu poder e Londres, como capital, era um ponto de encontro de múltiplas identidades transnacionais. Com 7,25 milhões de habitantes em 1914, a grande Londres tinha a maior

5 Para avaliar essa travessia de fronteira, examinei a frequência e o conteúdo de uma variedade de publicações impressas específicas para o contexto britânico, considerando não apenas como os eventos foram relatados, mas também em que tipos de publicação. Isso variou desde o Dancing Times, uma publicação mensal com foco em dança; até publicações semanais da sociedade, incluindo The Sketch, The Tatler e The Illustrated London News; e, finalmente, os jornais diários nacionais, tanto os broadsheets quanto os tablóides, incluindo o The Telegraph, o Daily Mail, o The Observer, o The Manchester Guardian, o Daily Mirror e o The Times. 
densidade populacional de qualquer centro urbano do mundo ocidental naquela época (GOEBEL; WHITE, 2016). Esse tamanho e influência, juntamente com os efeitos da industrialização do século XIX, viram o surgimento de um estrato de classes mais heterogêneo, especialmente a ascensão sem precedentes da classe média e da classe média alta. Essa foi uma situação potente e variada que afrouxou as restrições sociais e geográficas em torno de identidades aceitáveis e confrontou, especialmente para as mulheres, a modéstia contida e silenciosa das ideias vitorianas de corporalidade feminina (WALKOWITZ, 2003, p. 339). A mudança foi auxiliada por uma cultura impressa florescente que serviu para promover novas ideias sobre classe, nação, sexualidade e gênero (KELLY, 2004). Os espetáculos de dança solo protagonizados por mulheres tornaram-se aceitáveis e populares por meio de influências norte-americanas, como Isadora Duncan, e passaram a ser vistos como uma forma de cultura nacional (WALKOWITZ, 2003 , p. 338, 342). Esse ambiente pré-guerra estava maduro para, e celebrado na Salomania ambivalente e em busca de prazer que a dança de Allan passou a representar - uma constelação de sensações que os primeiros espetáculos em Londres de Pavlova reforçaram com a inclusão de espetáculos curtos primitivistas (ou de entretenimento) como Bacchanale e Valse Caprice (PRITCHARD, 2013, p. 63). O clima cultural carregado de Salomé da Londres do pré-guerra oferecia uma forma de feminilidade sancionada que era urbana, arrojada, em busca de prazer e permissiva, algo bem diferente do frenesi anti-Salomé durante os meses finais da guerra.

Ullah Maud Durrant, também conhecida como Maud Allan, chegou a esse ambiente progressista nas últimas semanas de fevereiro de 1908. Ela nasceu em Toronto em 1873, mas depois se mudou para São Francisco com sua família. Sua principal linha de estudo e habilidade era a música. Durante seus primeiros anos nos Estados Unidos, ela mostrou-se promissora como pianista, estudando em um conservatório local em São Francisco, e posteriormente mudou-se para Berlim, em 1895, para apri- morar suas habilidades e ampliar as possibilidades de uma carreira profissional (CHERNIAVSKY, 1991).

Perdendo o interesse pela música, ela começou a experimentar a dança de movimento livre/ revivalista grega popularizada por Isadora Duncan em 1899 e fez sua estreia na dança em Viena em 1903. Após um sucesso mediano, ela foi convidada para se apresentar em um evento privado realizado para Edward VII no resort de Marienbad no início de 1908, onde executou uma seleção de suas danças naturais gregas e seu trabalho orientalista, The Vision of Salome. Edward ficou muito impressionado com seu trabalho o que levou a uma apresentação a Alfred Butt, um dos principais empresários de Londres e gerente do Palace Theatre, onde ela foi contratada para uma temporada inicial de duas semanas. A partir desse momento, ela tornou-se uma sensação, da noite para o dia, e manteve esse sucesso pelos dois anos seguintes (WALKOWITZ, 2003). Essa fama estendeu-se para além do palco, na política e na alta sociedade e Londres.

Figura 2-Maud Allan com a Cabeça de João Batista.

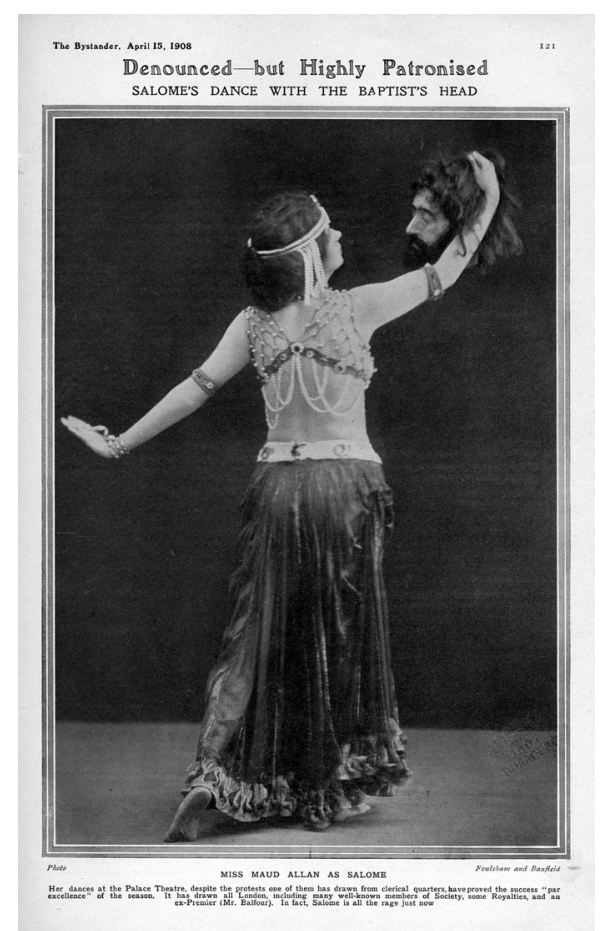

Fonte: () Illustrated London News Ltd/Mary Evans.

Todos os direitos reservados. 
Embora a maior parte da dança de Allan fosse no estilo de movimento natural inspirado na dança grega e realizada ao som de obras de compositores reconhecidos, incluindo Chopin e Mendelsohn ${ }^{6}$, sem dúvida o que fez sua fama e pelo que ela é lembrada foi sua interpretação dançada de Salomé7. Essa obra se baseou no personagem homônimo que ficou famoso com a peça de Oscar Wilde, em que Salomé concorda em dançar para o rei Herodes, seu tio, se ele lhe der a cabeça de João Batista. Nomeando sua versão de The Vision of Salome, Allan se apresentou com uma réplica de efeito realista da cabeça decepada de João Batista, uma experiência que o Financial Times descreveu como "magnífica em sua beleza sinuosa, seu clímax é tão horripilante a ponto de fazer a carne arrepiar e o sangue gelar".

6 As resenhas de seu trabalho, desde sua estreia em março de 1908 até as últimas notícias de sua primeira temporada em Londres, no final de 1909, podem ser encontradas em diversos jornais populares. Ver P.G.K., "Canadian Who Will Stir London," Daily Mail, 7 de março de 1908, UKpressonline; "The Poetry of Motion," Financial Times, 7 de março de 1908, Financial Times Historical Archive; "The Drama", London Daily News, 7 de março de 1908, The British Newspaper Archive; e "Srta. Maud Allan, the new dancer at the Palace Theatre," The Tatler Sporting and Country House Supplement, 11 de março de 1908.Mencionam The Vision of Salome, mas também indicam que seu programa apresentava muito movimento natural de inspiração grega que era frequentemente avaliado com entusiasmo.

7 É difícil encontrar qualquer comentário sobre Allan que, de alguma forma, também não mencione The Vision of Salome. Ver, por exemplo, Farfan (2015), "Masculine Women"; Bland (2013), Modern Women; Medd (2012), Lesbian Scandal; e Koritz (1995), Gendering Bodies/Performing Art. Existem também vários exemplos da influência de The Vision of Salome em seu público eduardiano, incluindo a paródia de Salomé "Sal Oh-My", que estreou no Alhambra logo após a estreia de Allan e a reprodução surpreendente da personagem Salomé de Allan por um grupo de meninas crianças empregado por outra paródia feita pela comediante musical eduardiana PhyllisDare. Ver "Dressed in a Chic Ventilation: Miniature Salomes," The Sketch Supplement, 24 de junho de 1908; e "The Vison of Salome 'Parodied:'Sal-oh-my '," The Sketch, 29 de abril de 1908.

8 "The Poetry of Motion," Financial Times, 7 Mar. 1908, Financial Times Historical Archive.
O que também é perceptível na versão de Allan é seu figurino de Salomé: esvoaçante, transparente, ornamentado de pérolas brancas e contas pretas, feitas para se parecerem surpreendentemente com seios. O figurino apresentava ainda uma longa saia preta translúcida com contas em forma de diamante incrustadas em sua bainha (ver Figura 2).

Qual foi realmente o movimento de Allan nessa obra é difícil de determinar. Enquanto Pavlova deixa para trás um filme, não existe nenhum exemplo em movimento da dança de Allan (WEIGARD, 1985) ${ }^{9}$. No entanto, embora em parte caricatural, o desenho de H.M. Brock abaixo, tirado da revista The Graphic, oferece algumas indicações de quais movimentos de Allan podem ter feito parte de suas danças de revivalismo grego e de sua interpretação de Salomé (ver Figura 3).

Figura 3 -Allandançando no Palace Theatre.

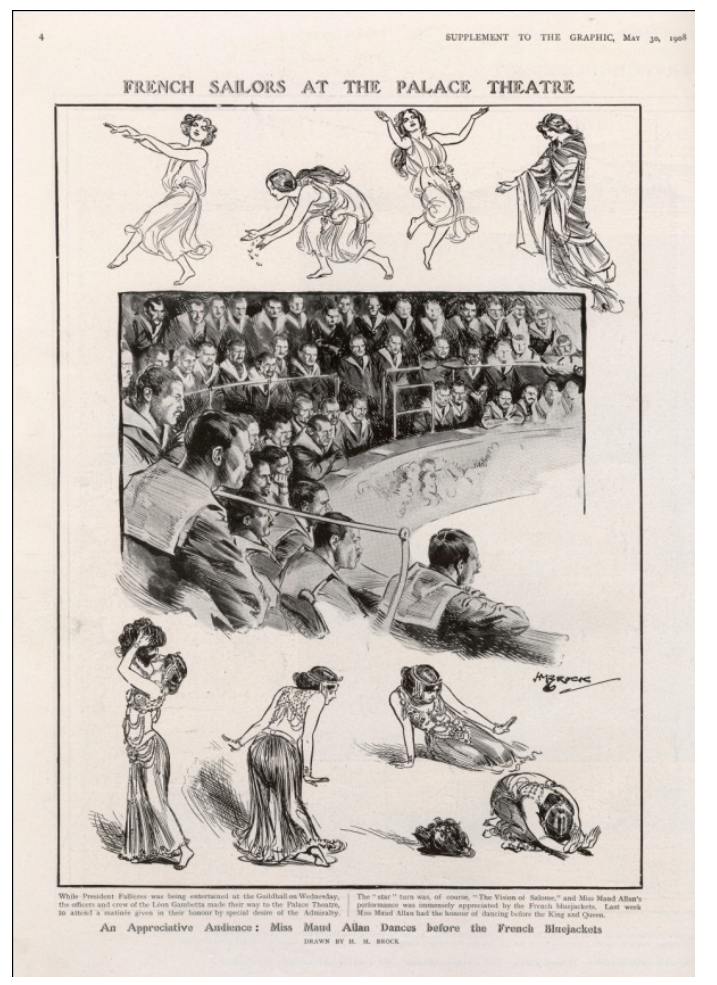

Fonte: () Illustrated London News Ltd/Mary Evans. All Rights Reserved.

9 Weigard (1982),"The Rugmaker's Daughter," sugere que o filme mudo feito por Allan em 1915 intitulado Rugmaker's Daughter incluía exemplos de dança grega e da obra The Vision of Salome; este filme foi perdido. 
Ao considerar o movimento de Allan nessas imagens, não é possível obter um sentido específico da dinâmica do movimento, das sequências dos movimentos ou da posição de Allan no palco. No entanto, eles nos dão uma sensação da tensão corporal de Allan e do fluxo do movimento; como ela usava os níveis descendo até o chão para se deitar ou se ajoelhar; e a intenção temática das sequências. Pode-se ter uma sensação do movimento de Allan pela forma como o tecido é desenhado e como o corpo está posicionado para indicar transferências de peso. A imagem superior ilustra seu movimento de inspiração mais grega que parece compreender o espaço energético das combinações de movimento; e a parte inferior indica um estudo mais estático no espaço. Em todos os casos, o que é evidente é a mobilidade e a amplitude do torso de Allan, seja curvando-se para trás ou para frente, e como essa liberdade no torso permite um repertório maior de expressão corporal na dança. Isso pode ser visto nos gestos do braço e, sem a restrição de calçados, a tensão e a posição dos pés oferecem uma dimensão adicional às qualidades expressivas da dança.

Entre sua estreia em 1908 e sua última temporada pré-guerra no Palace em 1911, Allan também manteve um portfólio significativo de comissões especiais e patrocínio privado, que incluiu apresentações apenas para convidados em eventos como festas privadas no jardim da elite cultural e política da capital (CHERNIAVSKY, 1991). Foi por meio dessas conexões que Allan tornou-se amiga íntima de Margot Asquith e de seu esposo, o então primeiro-ministro, Herbert Henry Asquith. Sempre vigilante para manter o decoro ainda ambivalente associado ao fato de ser uma artista solo, especialmente considerando o erotismo de sua Salomé no palco, Allan foi rigorosa na proteção de informações sobre sua vida pessoal e privada (MCDEARMON, 1987; WALKOWITZ, 2003). Isso era duplamente importante para Allan por causa do segredo que ela mantinha envolvendo seu irmão Theo, que foi preso, considerado culpado e executado em São Francisco pelo assassinato de duas mulheres em 1898 (CHERNIAVSKY, 1991). A asso- ciação com os Asquiths em particular a tornou uma figura pública cada vez mais observada ${ }^{10}$ por causa de opiniões polarizadas sobre as políticas de Asquith no percurso que levou à Primeira Guerra Mundial e à influência política frequentemente percebida como doentia de sua esposa Margot. Isso incluía rumores sobre a intimidade que ela compartilhava com marido e esposa (BLAND, 2013; MEDD, 2012).

Chegando a Londres no auge cosmopolita eduardiano, a dança de Allan contribuiu para um meio cultural que estava emergindo e desafiando a rigidez da era vitoriana, mudando a masculinidade do espaço social para um espaço em que as mulheres poderiam ocupar cada vez mais e participar ativamente. O contexto da imagem de Allan, realizada por Brock e demonstrada acima, com a inclusão marcante de seu público masculino poderia muito bem ter sido escolhida pelo The Graphic por seu potencial lascivo, mas o público do Palace era cada vez mais heterogêneo, tanto em termos de classe quanto de gênero (WALKOWITZ, 2003). A dança encontrou, cada vez mais, seu lugar nesse meio como agente de mudanças na composição e no consumo da cultura nacional. A popularidade de Allan, em meio ao apogeu da Londres eduardiana, capturou essa era de permissividade. A historiadora cultural Judith Walkowitz capta o que a força visceral e fantástica da performance dançada por Allan da personagem Salomé pode ter sido para o público da época ao descrever Allan como "um corpo feminino solitário, autônomo, sem restrições, móvel, pesado e com pouca roupa no corpo, cujo movimento delineou a interioridade emocional, estados de mudança de consciência e autoerotismo (WALKOWITZ, 2003, p. 340). De fato, o figurino orientalista sedutor e o dueto apaixonado com uma réplica realista de uma cabeça decepada, apresentada de forma visceral e expressiva em um solo de movimento "natural" exemplifica a rápida renegociação de formas tradicionais e aceitáveis de identidade que caracterizavam a sociedade eduardiana pré-guerra.

10 Popular with the Upper 10, Downing Street, The Sketch Supplement, 24 June 1908. 
Analisando Anna Pavlova, existem semelhanças interessantes com Allan. Ambas eram dançarinas estrangeiras. Pavlova nasceu em $1881^{11}$ (MONEY, 1982) em São Petersburgo, cerca de sete anos depois de Allan. Enquanto a formação de Allan era na música, Pavlova tinha formação especificamente em dança. Formou-se na Maryinsky Theatre School na Theatre Street em 1891 (KERENSKY, 1982). Ela imediatamente entrou no Imperial Ballet e embora sua constituição leve e seu estilo expressivo a posicionassem como um tipo diferente de outros destaques femininos como Mathilde Kschessinska (PRITCHARD, 2013, p. 10), ela contornou os escalões inferiores do corpo de ballet e rapidamente progrediu para se apresentar como uma artista solo. Pavlova começou uma turnê internacional em 1907 e na primavera de 1910 fez sua estreia pública em Londres no Palace Theatre, em um evento muito esperado e um sucesso sem precedentes $^{12}$. Ela dançava com Diaghilev e ex-colegas russos, mas como muitas das performers anteriores de dança solo vindas de outros países que transformaram o palco eduardiano, ela se concentrou em seguir uma carreira independente auxiliada por uma companhia complementar de dançarinos, que serviu de veículo para sua promoção. Como Allan, que fez extensas visitas internacionais profissionalmente, incluindo viagens aos Estados Unidos, África do Sul, Austrália e Índia, antes e durante a Primeira Guerra Mundial, Pavlova realizou extensas turnês mundiais, retornando apenas ocasionalmente à Europa. Assim como Allan, ela também visitou Hollywood, onde foi convencida a dançar em Dumb Girl of Porcini (1916). Ela comprou uma grande casa com jardins em Hampstead, norte de Londres, no

11 Há alguma incerteza quanto à sua data de nascimento. Ver Money (1982).

12 "The Palace: Mdlle. Pavlova," Daily Telegraph, 19 April 1910, The Telegraph Historical Archive; "World's Greatest Dancer: Pavlova in London," Daily Mail, 19 April 1910, UKpressonline; "Art, Music and the Drama," Illustrated London News, 23 April 1910; "Anna Pavlova," The Sketch Supplement, 20 April 1910; "The World's Greatest Dancer," The Tatler, 6 April 1910; "To Dance in England Again Before Long," The Sketch Supplement, 6 April 1910. início da década de 1920, que se tornou sua casa após a Revolução Russa. Allan também permaneceu em Londres até 1941 (CHERNIAVSKY, 1991).

Considerando sua contribuição para a dança, Pavlova pode ser vista como conservadora e sagaz nos papéis que desempenhou e criou para si mesma. Ela apresentou um repertório estabelecido de obras de ballet que em grande parte vieram da tradição imperial russa. Tais obras se tornaram as preferidas do público e, assim como Allan, Pavlova continuou essa abordagem de agradar o público em vez de seguir a atitude de vanguarda da arte mais elevada que seu compatriota Diaghilev estava popularizando simultaneamente. A carreira que ela construiu mostrou uma compreensão de como manipular e encenar suas performances, por exemplo, organizando o Palace Theatre como palco para sua estreia em Londres em 1910, o mesmo teatro que foi associado ao enorme sucesso de Allan. E, como observado anteriormente, Pavlova alterou os programas de seus espetáculos para atrair o mesmo tipo de popularidade que a dança de Allan desfrutava. A criação magistral de sua persona pública estava atrelada e reforçada por seus sucessos de bilheteria, que se baseavam em rumores provocantes mantidos por um silêncio absoluto sobre os aspectos de sua vida privada (MONEY, 1982). Por exemplo, desde o início de sua carreira, Pavlova teve uma relação ambígua com Victor Dandre, um White Russian e ex-membro da Duma. Seu papel nunca foi realmente determinado, mas ele foi apontado de várias maneiras como seu empresário, uma figura paterna ou seu marido (PRITCHARD, 2013). Isso manteve as plateias e o público em dúvida, o que reforçou sua imagem pública. Essa supressão escrupulosa de dados pessoais, como no caso de Allan, pode ter tido propósito de ocultar informações potencialmente prejudiciais. Por exemplo, havia rumores de que Pavlova era ilegítima e judia (KERENSKY, 1982) e, embora isso certamente não fosse tão explosivo quanto ter um irmão assassino, ambas as categorias poderiam levar ao estigma social. E, como veremos a partir do exemplo de Allan no período do final da guerra, isso acarretou punições pesadas. 
Assim como Allan, Pavlova teve um trabalho marcante ao longo de sua carreira que passou a ser firmemente associado à sua personalidade pública e celebridade. A obra intitulada The Swan, Le Cygne, ou mais popularmente, The Dying $S w a n^{13}$ é uma obra curta de apenas três minutos ao som da música de Camille Saint-Saëns. Foi criada entre 1905 e 1907 em São Petersburgo pelo então emergente coreógrafo russo Michel Fokine com Pavlova como dançarina (KERENSKY, 1982) e, como a obra bem conhecida de Allan, tem conotações mórbidas, representando o momento final na vida de um cisne. O diferencial em relação ao exemplo de Allan é que a filmagem de Pavlova dançando The Dying Swan ainda existe e a obra teve muitos intérpretes depois dela, servindo como uma espécie de termômetro da legitimidade da bailarina. $\mathrm{O}$ aspecto proeminente $\mathrm{e}$ inovador do curto trabalho é sua execução quase inteiramente usando o passo bourrée, em que a dançarina se impulsiona pelo espaço do palco enpointe com uma sucessão de pequenos passos e o corpo completamente imóvel, como se flutuasse em águas calmas. Também apresenta movimentos de braço coreografados, ou ports de bras, nos quais os braços imitam o movimento sequencial contínuo das asas de um pássaro enquanto voa. Em The Dying Swan, uma figura singular em tutu completo e enpointe entra de costas e quase languidamente se desloca em bourré, com movimentos sinuosos de braços alados. Isso é seguido por momentos de pausa em que ela permanece como se estivesse atormentada. Ela sucumbe cada vez mais à gravidade, como se desmaiasse, e parece se recompor apenas para admitir o inevitável, enquanto afunda final e irrevogavelmente no chão. Todo o efeito é surpreendentemente zoomórfico e antropomórfico, já que a figura dançante parece alternar entre uma mulher dançando e o cisne que ela está representando.

Assim, embora existam alguns pontos de partida significativos, há também algumas semelhanças impressionantes entre essas duas mulheres dentro

13 Eu uso Dying Swan para me referir à obra como um todo. do contexto do meio cultural londrino do pré-guerra em que ambas foram introduzidas. A próxima seção apresenta considerações mais específicas sobre como suas carreiras divergentes após a Primeira Guerra Mundial oferecem um meio de compreender as consequências das ideias em rápida mudança sobre masculinidade e feminilidade no início do século $X X$. Faço isso com referência específica a dois eventos: o caso de difamação de Allan em 1918 e a morte de Pavlova em 1931. Esses eventos ilustrarão como as histórias bifurcadas de Allan e Pavlova podem ser entendidas como moduladoras de atitudes na era pós-Primeira Guerra Mundial, comportamentos que incluíam expressões públicas de raiva e medo associados ao pânico moral e à xenofobia, bem como pesar e tristeza associados ao luto em massa. Em última análise, sugiro que se tratava de como a dança dessas mulheres passou a significar coisas diferentes sobre as maneiras como as mulheres devem ser entendidas para o funcionamento de uma ordem social "saudável".

Figura 4 - Anna Pavlova as the Dying Swan.

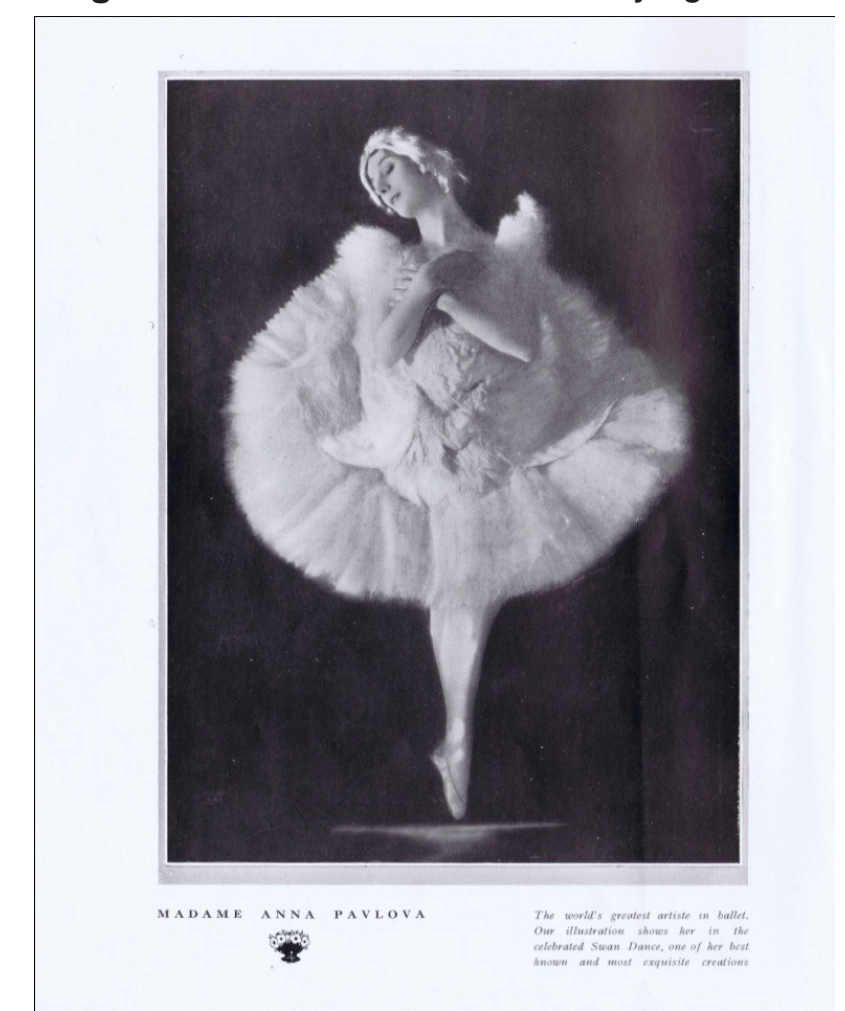

Fonte: @ Mary Evans / JazzAge Club Collection. Todos os direitos reservados. 


\section{Depravação, sacrifício, reintegração}

Durante os últimos meses de 1917, Allan voltou para realizar uma temporada em Londres após uma ausência de vários anos. Esta não era a cintilante belle époque de Londres do pré-guerra. O país estava deprimido com a escassez nos lares e o pesado fardo emocional da catastrófica perda de vidas. As terríveis perdas da Batalha de Passchendaele foram seguidas no ano novo por rumores de uma colossal ofensiva alemã planejada para a primavera (KETTLE, 1977). A sorte de seus amigos íntimos, os Asquiths, também estava em declínio. Surpreendentemente, as apresentações de Allan foram bem visitadas pelo público e ela ainda estava recebendo boas avaliações dos críticos $^{14}$. Ela estava em negociações com o London Royal Court Theatre, que estava planejando produzir uma versão da peça Salome de Oscar Wilde. As apresentações públicas da peça ainda estavam proibidas pelo gabinete oficial do Lord Chamberlain, então o evento deveria ser privado. Nele, Allan interpretaria sua famosa The Vision of Salome que teria algumas falas na esperança de que isso a levasse também a uma carreira de atriz. Como era comum em eventos privados, uma lista foi colocada na seção de anúncios classificados do The Times solicitando manifestação de interesse. Em resposta ao anúncio, um pequeno jornal de extrema direita chamado The Vigilante, dirigido por Noel Pemberton Billing, publicou esta pequena notificação provocativa.

\section{O culto ao clitóris}

Para participar da performance de Maud Allan na Salome de Oscar Wilde, é preciso solicitar acesso à Miss Valetta, na Duke Street n. 9... Se a Scotland Yard se apoderasse da lista desses participantes, não tenho dúvidas de que conseguiriam os nomes de vários milhares dos primeiros 47.000 (MEDD, 2012, p. 28).

Os 47.000 referem-se a uma lista identificada em um artigo anterior em The Vigilante, escrito por Billing, como um grupo de homens e mulheres na sociedade britânica que eram suscetíveis à chantagem

14 Maud Allan's Return, The Tatler, 14 de novembro de 1917. por agentes alemães devido às suas perversões sexuais ocultas. Allan, vendo o artigo, foi compelida a processar por difamação, argumentando que o "culto ao clitóris" a estava caluniando ao chamá-la de lésbica. Os termos do processo foram publicados integralmente no The Times com o termo "lesbianismo" aparecendo pela primeira vez na imprensa na Inglaterra (MEDD, 2012). Como no julgamento de Wilde quase 25 anos antes, embora Allan tenha movido a ação contra Billing, foi ela quem acabou sendo julgada por imoralidade sexual, bem como, de forma ainda mais assustadora, como uma potencial inimiga do estado. O julgamento começou em 29 de maio de 1918 e durou seis dias. Todos os principais jornais britânicos relataram detalhes do andamento, tendo o Daily Mirror apresentado duas fotos escandalosas do julgamento durante este período ${ }^{15}$. Billing promoveu a opinião de que os alemães eram libertinos e aqueles que se infiltraram na Grã-Bretanha como espiões espalharam doenças venéreas e homossexualidade para minar o esforço de guerra britânico (MEDD, 2012). Suas testemunhas incluíam o ex-amante de Oscar Wilde, Alfred Lord Douglas e Eileen Villiers-Stuart, que alegou ter visto a lista mencionando que incluia também o juiz desse litígio, Charles Darling. Além disso, Billing afirmou que um grupo de mulheres da sociedade londrina era formado por homossexuais praticantes que vendiam segredos aos alemães. Alimentado pela privação do que parecia uma guerra sem fim e pela a ansiedade sobre uma ofensiva alemã de sucesso contínuo na França (KETTLE, 1977), o julgamento produziu um frenesi repleto de fofocas lascivas sobre o relacionamento anterior de Allan com Margot Asquith, rumor que em seu ápice

15 Ver "P.B. Libel Charge," Daily Mirror, 31 de maio de 1918, UKpressonline; "Scenes at Billing Trial," Sunday Times, 2 de junho de 1981, Sunday Times Digital Archive; "The Billing Trial," Daily Mail, 5 de junho de 1918, UKpressonline; "Mr. Billing Acquitted," The Manchester Guardian, 5 de junho de 1918, ProQuest Historical Newspapers; "Acquittal of Mr. Billing," The Times, 5 de junho de 1918; "Pemberton Billing Trial," Daily Telegraph, 5 de junho de 1918, The Telegraph Historical Archive; and "The Defendant cheered by the crowd," Daily Mirror, 5 de junho de 1918, UK pressonline. 
da opinião pública também feriu Allan. A conexão de Allan com seu irmão foi exposta por Billing para mostrar que a perversão sexual estava diretamente relacionada à genética. $O$ tribunal decidiu a favor de Billing, que recebeu grande apreço tanto no tribunal abarrotado quanto nas ruas lotadas do lado de fora. Isso efetivamente encerrou a carreira de Allan e a carreira de qualquer pessoa associada a ela.

No frenesi público moral que caracterizou o julgamento de Billing, podemos testemunhar o que Shoshana Felman define em sua exploração inovadora do testemunho de trauma, como "o estado de ser atingido, ferido pela realidade" (FELMAN, 1992, p. 28). Aplicado aos britânicos do final da guerra, o que fica em destaque é como o evento articulou essa ferida e ilustrou um momento histórico em que uma cultura pode ter sido entendida como se estivesse se desfazendo. Normas e crenças tranquilizadoras sobre identidade são repentinamente, agressivamente questionados e trazem indicadores específicos de trauma, incluindo medo, violência, retraimento e apreensão. Além disso, como já argumentei (THOMS, 2013), a ferida da realidade que provoca o trauma é uma complexa teia de efeitos envolvendo múltiplos atores que são afetados individualmente, mas também coletivamente. Uma pessoa não pode agir sem algum tipo de influência sobre a outra, mesmo que de forma desconhecida ou velada. Citando Cathy Caruth, assim como o trauma, "nunca apenas de si [...], história é a maneira como todos estamos envolvidos nos traumas uns dos outros" (CARUTH, 1996, p. 24). Os efeitos do trauma surgem não apenas na experiência de um evento materialmente catastrófico, embora a especificidade e o impacto dessa experiência singular não possam ser subestimados; é a maneira como o acontecimento se enquadra em um contexto histórico emaranhado de valores e significados socioculturais que informam o dano psíquico e sua atenuação. Na verdade, o evento em si pode não ser traumático no início, mas se torna traumático na maneira como é abordado por atores sociais e instituições.
Assim, o julgamento de Billing forneceu um veículo conveniente para combinar e articular traumas associados a uma série de mudanças culturais influenciadas direta e indiretamente pela guerra. A guerra no continente estava entrando em seu quarto ano, com crescente confusão social e inquietação doméstica (KENT, 2009). A questão da independência da Irlanda e com ela as preocupações sobre a integridade do Império acabavam de chegar ao auge com a violenta erupção da Revolta da Páscoa em 1916. O crescimento do Partido Trabalhista também desafiou o status quo tradicional, dando voz política às populações da classe trabalhadora, especialmente com o Representation of the People Act em fevereiro de 1918, que concedeu sufrágio limitado às mulheres pela primeira vez na história britânica e emancipou todos os homens acima de 21 anos de idade. De fato, este último exemplo destaca o papel cada vez mais desafiador que o gênero desempenha na compreensão dos limites da realidade social. Essas mudanças rápidas, bem como a histeria de Londres na primavera de 1918, ajudaram a preparar a cena para o que se tornou um julgamento sobre a própria identidade feminina. Aqui, a questão da "mulher" veio a articular os fundamentos sobre os quais o trauma da desintegração do sistema de crenças e identidades reconhecíveis foi negociado e é revelador que o julgamento e a execução por pelotão de fuzilamento da dançarina Mata Hari sob falsas acusações de espionagem ocorreram apenas seis meses antes do julgamento ${ }^{16}$.

O ponto central, então, do exemplo de Allan, é a ansiedade sobre sua identidade como algo cognoscível e controlável; em grande escala é a ansiedade em relação à incapacidade de diferenciar amigo e inimigo, que foi habilmente representada nas discussões de Billing sobre as conexões ocultas entre perversão sexual, genética e traição. Medd argumenta brilhantemente (MEDD, 2012) que

16 Mata Hari foi executada em 17 de outubro de 1917. Ver Wheelwright (1992, p. 4), The Fatal Lover, que escreve de forma perspicaz "Mata Hari trouxe medo de um inimigo alienígena, a mulher rebelde e a decadência sexual". 
o julgamento por difamação ofereceu um substituto para uma guerra incompreensível, demonstrada na incognoscível identidade lésbica. Eu tenho uma visão um pouco mais ampliada e sugiro que não seja simplesmente a forma com que um momento cultural é desestabilizado pelo surgimento da identidade lésbica, mas como o surgimento da identidade lésbica provoca um abismo ontológico de identidade. O julgamento de Billing ampliou a visão da impossibilidade de apreender totalmente a magnitude traumática da guerra, fornecendo um evento que colocou em questão a própria relação entre gênero e sexo, cultura e biologia, e segundo Judith Butler (BUTLER, 1990), dissolveu o entendimento dado como certo de que identidade é igual à realidade. Devemos ser capazes de distinguir entre homens e mulheres e, quando não conseguimos, questionamos o próprio tecido da nossa existência. Achamos que sabemos o que é "mulher", mas de repente as mulheres parecem se comportar muito como homens e, simultaneamente, pensamos que conhecemos "homens", mas por causa dos acontecimentos da grande guerra, a identidade dos homens, como Joanne Bourke persuasivamente argumenta, também é significativamente alterada (BOURKE, 1996).

Ao destacar a crise social potencial instituída em torno das categorias de masculinidade e feminilidade, o julgamento de Billing destaca como o gênero é uma impressionante constelação de traumas. Por constelação de traumas, entendo um conjunto de traumas inter-relacionados e seus efeitos (medo, raiva, retraimento, psicose) que operam em relação à identidade de gênero. "Gênero é traumático e trauma está ligado a gênero", como nos lembra Tiffany Joseph (JOSEPH, 2003, p. 67). Em julgamento estava precisamente a figura pré-guerra da dançarina solo que o exemplo de Allan encapsulou. Essa figura representou e uniu-se à ferida avassaladora da realidade da grande guerra. Sua dança sem restrições veio a demarcar limites traumáticos de identidade. O julgamento feito publicamente manifestou emoções muito cruas e profundamente perturbadoras sobre a guerra por meio de um questionamento so- bre o que constituía a identidade e o papel adequados para as mulheres. Ao fazer isso, a punição de Allan foi garantida, pois ela, e por associação sua dança, se tornaram insustentáveis para a ordem social. Ela tornou-se a vítima dessa ferida ainda aberta.

Se Allan e sua dança de Salomé foram catalisadoras da profunda e contínua ansiedade sobre a identidade feminina e do papel da feminilidade para a integridade da nação, a morte de Pavlova, treze anos depois, pode ser entendida como um paliativo do corpo político ao repatriar identidades de gênero reconhecíveis. Seu falecimento em 23 de janeiro de 1931 em Haia foi amplamente divulgado na imprensa britânica ${ }^{17}$ e, como o Julgamento de Billing, despertou interesse público em massa. Dessa vez, porém, unido em expressões de pesar. As circunstâncias que envolveram sua morte acrescentaram motivação para a percepção pública de tragédia, que representaram a imagem de uma mulher graciosa, dedicada, corajosa e acima de tudo abnegada. Como observado anteriormente, Pavlova foi prolífica em suas turnês e, por meio delas, teve um grande número de seguidores internacionais, admiradores fervorosos e críticos. No final da década de 1920, seu zelo pela promoção da dança fez com que ela tivesse visitado todos os continentes, tendo se apresentado em

17 The Daily Express destacou a notícia da morte dePavlova na sua capa. Ver "Pavlova Dead," Daily Express, 23 de janeiro de 1931, UKpressonline. The Manchester Guardian noticiou também naquele mesmo dia. Ver "Death of Mme Pavlova: Illness during Tour of Holland," The Manchester Guardian, 23 January 1931, ProQuest Historical Newspapers. The Manchester Guardian publicou no dia seguinte "Our London Correspondence: Pavlova as a Friend," The Manchester Guardian, 24 de janeiro de 1931, ProQuest Historical Newspapers. Ver também "Pavlova Dead," Daily Express, 23 de janeiro de 1931, UKpressonline; G.B. "Pavlova Lies in State," Daily Express, 29 de janeiro de 1931, UKpressonline; e "Personalities of the Week," Illustrated London News, 31 de janeiro, 180. Elogios e homenagens registrados na imprensa se estenderam até a primavera de 1931. Ver como exemplo, "Pavlova Memoria - Special Performance attheHippodrome," The Times, 16 de fevereiro de 1931, Times Digital Archive; "Anna Pavlova: Some Memories," Dancing Times, março de 1931, p. 683-692; "The Royal Academy, 1931: A Memoryof a GreatDancer," Illustrated London News, 9 de maio de 1931. 
lugares como Egito, África do Sul, Índia, Sri Lanka, Japão, Venezuela, Peru, Nova Zelândia, Austrália, Canadá e Estados Unidos, com longas temporadas em Nova York. No entanto, no final da década de 1920, a economia mundial estava em crise profunda, precipitando viagens ainda mais extensas. Nessa época, Pavlova estava com mais de 40 anos sofrendo de um constante estado de exaustão e um problema persistente no joelho. Retornando à Europa na primavera de 1930, ela continuou a fazer turnês durante o outono e iria fazer uma turnê pelo norte da Europa no início do ano seguinte. Viajando no início de janeiro, o trem de Pavlova descarrilou durante a noite e uma peça de bagagem a atingiu no peito enquanto ela estava dormindo. Várias fontes também relataram que ela ajudou no desembarque de outros sobreviventes feridos com pouca preocupação com seu próprio bem-estar. Isso foi seguido por um atraso de meio dia esperando ao ar livre e em compartimentos de trem sem aquecimento. Ela já apresentava sinais significativos de doença na viagem seguinte de trem para Haia, onde a turnê deveria começar. Essa doença foi diagnosticada dias depois como pleurisia, que continuou a piorar. Pavlova supostamente recusou-se a submeter-se a uma operação para aliviar a pressão em seus pulmões porque isso ameaçava encerrar sua carreira na dança. Ela morreu no início da noite de 22 de janeiro de 1931, e foi relatado que suas últimas palavras foram para que seu vestido de cisne ficasse pronto (MONEY, 1982).

Ao pensar sobre a dinâmica do efeito traumático, a morte de Pavlova oferece várias percepções. Certamente, como explorarei a seguir, é uma elaboração coletiva de ansiedades culturais por meio do luto público que valoriza a feminilidade tradicional. Em primeiro lugar, como um resultado importante, a questão do trauma e da temporalidade deve ser considerada. A complexidade do efeito traumático está no fato de não ser totalmente disponível, emergindo em fenômenos perturbadores sofridos como uma resposta tardia à experiência. O tempo traumático não é percebido como o fluxo coerente de eventos que caracteriza a realidade social normal, mas sim como um palimpsesto de temporalidades concorrentes com estados confusos de consciência. É experimentado como uma onipresença esmagadora no agora. Essa falta de noção da passagem do tempo também influencia a defasagem temporal associada aos efeitos posteriores do trauma. Ann Douglass e Thomas Vogler (2013), por exemplo, usam a progressão de vinte anos de reconhecimento público e envolvimento com o Holocausto para ilustrar esse efeito. O tempo traumático, então, também pode fornecer uma compreensão diferente de eras históricas e seus efeitos continuados. Embora os procedimentos associados à morte de Pavlova em 1931 possam estar claramente ligados à segunda metade do período entre guerras, o amplo espaço de tempo do efeito traumático o conecta às influências de uma era sócio-histórica anterior. Vale a pena reiterar que a Primeira Guerra Mundial foi um acontecimento que, na época, ultrapassou as fronteiras da imaginação humana e suas múltiplas influências em eventos posteriores não podem ser subestimadas. Suas ressonâncias traumáticas reverberaram pela primeira metade do século XX e possivelmente além.

No contexto dessa resposta atrasada, as reações à morte de Pavlova também coincidem com o pensamento de Susan Kent sobre os sintomas sociais do trauma. Kent explora a psique britânica do pós-guerra e do entreguerras e sua influência na política da época. Ela sugere que o "choque de bomba" teorizado como consequência da guerra foi sentido coletivamente e articulado em inúmeros depoimentos de combatentes e civis que sentiram terem sido "feitos em pedaços, fragmentados em sua existência, totalmente paralisados em relação ao fluxo do que deveria ter sido suas vidas naturais" (KENT, 2009, p. 3). O desejo de se sentir completo novamente e de curar a psique nacional levou ao apelo generalizado da política conservadora com a intenção de definir e policiar de perto as fronteiras do eu "inglês" contra o que era percebido como pernicioso e invasivo, incluindo várias organizações religiosas, mulheres, grupos raciais e étnicos. Se o julgamento interposto por Allan articulou temores sobre uma profunda 
confusão a respeito dos limites da identidade feminina, a morte de Pavlova, mais de uma década depois, pode ser entendida como tendo ajudado a restabelecer esses limites. O cultivo progressivo e cuidadoso da imagem de Pavlova tornou-a epítome de pureza, modéstia e dedicação envolta em uma aura de graça e beleza. As circunstâncias de sua morte reforçaram essa imagem de forma ainda mais enfática. Seu sacrifício não foi simplesmente desistir de tudo por sua arte, mas também morrer por ela. Sua identidade é digna de luto, e o luto é mais profundo por causa do valor de sua identidade. Ela não era apenas a intérprete por excelência dessa graça submissa e dessa rendição, mas também sua personificação literal. Sua morte proporcionou um evento que retornou e afirmou uma categoria de feminilidade que era reconfortante e quantificável. Ela recuperou gênero e sexo e ofereceu um remédio para psicose. Enquanto a melancolia, teorizada por Sigmund Freud em 1917, caracteriza-se por uma incapacidade de identificar a natureza específica da perda, bem como sentimentos de insignificância, o luto é um processo de reconhecimento da perda e de reintegração social. Diante do agravamento da crise financeira global e do aumento da instabilidade sociopolítica que acompanhou a ascensão de Hitler ao poder na Alemanha - todas consequências assustadoras do fracasso da reconciliação pós-Primeira Guerra Mundial - o luto por Pavlova ofereceu o conforto de comemorar ideias reconhecíveis, louváveis e controláveis sobre as mulheres, fundadas em compreensões tradicionais de feminilidade.

The Dying Swan pode ser visto como tendo um papel central na valorização da feminilidade tradicional como um sedativo social, uma afirmação que se torna mais durável se mapearmos a jornada de influência da obra desde sua estreia em Londres antes da guerra, até os anos 1920 e na década de 1930 após a morte de Pavlova. É perceptível que a personalidade profissional de Pavlova muda de modo que em meados da década de 1920 em Londres, ela adotou totalmente o que Jennifer Fisher chamou de "a marca do cisne" (FISHER, 2012, p. 51). No entanto, enquanto dançava The Dying Swan em seus primeiros espetáculos pré-guerra no Palace em 1910, foram as danças exuberantes e sensuais em parceria com Mikhail Mordkin que seus administradores encorajavam e que a imprensa noticiava, apresentando o caráter alegre e sem restrições da dança natural grega. Isso pode ser testemunhado em espetáculos como seu Bacchanale, que foi destaque em material de promoção e cobertura da imprensa com uma foto provocativa de Pavlova segurando um cacho de uvas perto da boca e olhando por cima do ombro em um convite picante ${ }^{18}$. Após o outono de 1914, Pavlova somente voltou a Londres no pós-guerra, em 1920, desta vez, aparentemente evitando o Palace onde ela e sua companhia tiveram todas as suas temporadas pré-guerra em Londres e, ao invés disso, aparecendo em teatros do West End, como Drury Lane e Covent Garden. Para alguém cuja escolha de se apresentar especificamente no Palace para sua estreia em Londres em 1910 buscando associação com Allan, essa mudança parece reveladora. Este retorno de 1920 também foi relatado em vários jornais com referência específica à mundialmente famosa dança do cisne, que foi relatada como mais bonita do que nunca após uma ausência de quatro anos $^{19}$. Em 1925, ilustrando o maior alargamento do alcance social e do impacto do emblema do cisne, o hoteleiro Gordon Selfridge exibia uma vitrine mostrando uma réplica de Pavlova no palco em uma pose clássica da obra. Uma imagem dessa réplica foi apresentada no periódico The Sketch ${ }^{20}$. Esta conexão também ilustra como a imagem de Pavlova estava ligada ao comércio dos anos 1920, que oferecia o novo e o erótico - mais romântico do que erótico - em espaços seguros e controlados (DENNIS, 2008).

18 Página inicial de The Sketch Supplement, 20 de abril de 1910.

19 Pavlova's return' Enthusiastic Welcome at Drury Lane, The Times, 13 de abril de 1920, Times Digital Archive; "London Theatres. Drury Lane. Return of Pavlova," The Stage, 15 de abril de 1920.

20 Commerce pays a tribute to the great art of Mme. Pavlova, The Sketch, 4 de novembro de 1925. 
No entanto, o vínculo mais profundo entre $\mathrm{Pa}$ vlova e o cisne vem com sua morte. Isso inclui anúncios de obituário que apresentavam descrições de Pavlova fazendo movimentos de "cisne" pouco antes de morrer ${ }^{21}$; imagens dela abraçando um cisne ${ }^{22}$; "cartas ao editor" refinando pontos feitos em seu obituário publicado anteriormente para incluir "tais milagres de interpretação como o cisne ${ }^{23}$;" e ensaios fotográficos destacando o cisne como sua obra-prima ${ }^{24}$. Todos esses relatos de sua morte reforçam a sua imagem icônica onipresente como o cisne morrendo. Perversamente, como um contraponto para a "luxúria voraz" da personagem Salomé, The Dying Swan veio a defender que a própria morte é uma característica positiva da feminilidade hegemônica. Na verdade, o papel de Pavlova como o cisne morrendo fez cada vez mais sua história pessoal já ser uma história sobre a morte e a cura da tragédia dessa morte.

Pavlova interpretando o cisne, portanto, parece servir como um símbolo poderoso para obliterar as transgressões femininas celebradas na Salomania do pré-guerra e se transforma na figura trágica do cisne que atenua os medos incontroláveis associados à feminilidade moderna. O poder social da metáfora é ainda mais evidente considerando a forma com que as duas mulheres foram relatadas na história. Talvez seja revelador que a memória de Pavlova e sua influência tenham experimentado status continuado de mito. Muito do trabalho relativo a Pavlova é hagiográfico e destina-se tanto ao impacto visual quanto textual (MONEY,1982). Há pouca discussão sobre o impacto crítico que a dança e a celebridade de $\mathrm{Pa}$ vlova tiveram nas diferentes formações sociais dos últimos 100 anos. Para ter certeza, sou provocada

21 Obituary - Anna Pavlova, The Stage, 29 de janeiro de 1931.

22 Personalities of the Week, Illustrated London News, 31 de janeiro de 1931.

23 Points from Letters, The Times, 26 jan. 1931, Times Digital Archive.

24 Anna Pavlova: Famous Dancer's Covent Garden Triumphs, The Times, 24 de janeiro de 1931, Times Digital Archive. a ler essa carência como um efeito daquelas figuras públicas que não podemos ou não iremos avaliar criticamente por medo de minar uma frágil fantasia de plenitude e totalidade. "Pavlova" como ideia oferece um analgésico social, proporcionando sustentação de fantasias hegemônicas sobre a mulher ideal como bonita, abnegada, adequada e, claro, heterossexual.

Por outro lado, até o final da década de 1970, Allan praticamente desapareceu da memória cultural (MCDEARMON, 1978). Ela foi resgatada da obscuridade nas últimas décadas por um interesse sustentado por ela nas áreas de Estudos de Gênero, Estudos da Mulher e Estudos Culturais, onde seu exemplo ofereceu espaço para as discussões culturais necessárias(FARFAN, 2015; BLAND, 2013; MEDD, 2012; WALKOWITZ, 2003; KORITZ, 1995; HOARE, 1997; KETTLE, 1977). Eu argumentei que os exemplos de Allan e Pavlova oferecem uma maneira de entender como o gênero foi uma constelação de traumas para a era da Primeira Guerra Mundial e talvez essa controvérsia seja ilustrada com mais força em como a memória de Allan desapareceu de uma forma tão significativa. Em seu aclamado livro sobre a complexidade da memória, Susan Rubin Suleiman (2012) sugere que o passado é lembrado na forma como uma cultura se entende e como deseja ser compreendida pelos outros. Nos anos pré-guerra, Allan e Pavlova eram dançarinas promissoras com uma carreira pela frente, ligadas não apenas pelo teatro em que estrearam, mas também pela perpetuação da liberdade (feminina) associada à dança natural. Seria também um efeito traumático da guerra lembrar e celebrar a representação dos momentos finais de um belo mas condenado cisne, em vez da representação da autonomia e da autoconfiança feminina reunidas na figura de Salomé?

\section{Referências}

BLAND, L. Modern women on trial: Sexual transgression in the age of the flapper. Oxford and New York: Oxford University Press, 2013. 
BOURKE, J. Dismembering the Male:Men's bodies, Britain and the Great War. London: Reaktion Books, 1996.

BUTLER, J. Gender Trouble: Feminism and the Subversion of Identity. New York: Routledge, 1990.

CASEY, C. G. "Pavlova and her Daughters: Genealogies of Contingent Autonomy". In: BALES, M.; ELIOT, K. (Eds.). Dance On its Own Terms: Histories and Methodologies. p. 207-228. Oxford and London: Oxford University Press, 2013.

CARUTH, C. Unclaimed Experience: Trauma, Narrative, History. Baltimore and London: Johns Hopkins University Press, 1996.

CHERNIAVSKY, F. The Salome Dancer: The life and times of Maud Allan. Toronto: McClelland and Stewart Inc., 1991.

DENNIS, R. Cities of Modernity: Representations and Production of Metropolitan Space 1840-1930. Cambridge: Cambridge University Press, 2008.

DOUGLASS, A.; VOGLER, T. Introduction. In: DOUGLASS, A.; VOGLER, T. (Eds.). Witness and Memory: The Discourse of Trauma. p. 9-13. New York and London: Routledge,2003.

FARFAN, P. Masculine Women and Effeminate Men: Gender and Sexuality on the Modernist Stage. British Theatre and Performance 1900-1950. Ed. R. D'Monte. London: Bloomsbury, p. 213-222, 2015.

FELMAN, S; LAUB, D. Testimony: Crises of Witnessing in Literature, Psychoanalysis and History. New York: Routledge, 1992.

FENSHAM, R. Nature, Force, Variation. In:CARTER, A.; FENSHAM, R. (Eds.). Dancing Naturally: Nature, Neo-classicism and Modernity in Early Twentieth-Century Dance.p. 1-15. Basingstoke and New York: Palgrave Macmillan, 2011.
FISHER, J. The Swan Brand: Reframing the Legacy of Anna Pavlova. Dance Research Journal,v.11, n. 1, p. 51-67, 2012.

GLASSTONE, R. Book Reviews: Keith Money, Anna Pavlova: Her Life and Art. Dance Research, v. 2, n. 1, p. 68-73, 1984.

GOEBEL, S; WHITE, J. London and the First World War. The London Journal, v.41, n. 3, p. 199-218, 2016.

HOARE, P. Wilde's Last Stand: Decadence, conspiracy and the First World War. London: Duckworth, 1997.

JOSEPH, T. Non-Combatant's Shell-Shock: Trauma and Gender in F. Scott Fitzgerald's Tender Is the Night. Feminist Formations, v. 15, n.3, p. 64-81, 2003.

KELLY, K. E. Seeing Through Spectacles: The Woman Suffrage Movement and London Newspapers, 1906 - 13. European Journal of Women's Studies, v. 11, n. 3, p. 327-353, 2004.

KENT, S. K. Aftershocks: Politics and Trauma in Britain, 1918-1931. Basingstoke: PalgraveMacmillan, 2009.

KERENSKY, O. Review: Searching for a Legend. Dance Chronicle, v. 6, n. 1, p. 79-83, 1982.

KETTLE, M. Salome's Last Veil: The libel case of the century. London: Hart-Davis MacGibbon, 1977.

KORITZ, A. Gendering Bodies/Performing Art: Dance and Literature in early Twentieth Century British Culture. Ann Arbor: University of Michigan Press, 1995.

MEDD, J. Lesbian Scandal and the Culture of Modernism. Cambridge and New York: Cambridge University Press, 2012. 
MCDEARMON, L. Maud Allan: The public record. Dance Chronicle, v. 2, n.2, p. 85-105, 1978.

MONEY, K. Anna Pavlova: Her Life and Art. London: Harper Collins, 1982.

OVERY, R. The Morbid Age: Britain and the Crisis of Civilization, 1919-1939. London: Penguin, 2009.

PATTERSON, A. Maud Allan, the cult of the clitoris and the future of Britain. In:DEAREY, M.; NICOLÁS, S.; DAVIS, R. (Eds.). Re-visiting Female Evil: Power, Purity and Desire. Boston: Brill-Rodopi, p. 2-10, 2017.

PRITCHARD, J. Anna Pavlova: Twentieth Century Ballerina. London: Booth-Clibborn Editions, 2013.

SULEIMAN, S. R. Crises of Memory and the Second World War. London: Harvard University Press, 2012.

SYMONS, M. The Confection of a Nation: The social invention and social construction of the Pavlova. Social Semiotics, v. 20, n. 2, p. 197-217, 2010.

THOMS, V. Martha Graham: Gender and the Haunting of a Dance Pioneer. Bristol and Chicago: Intellect, 2013.

WALKOWITZ, J. R. The Vision of Salome: Cosmopolitanism and Erotic Dancing in Central London, 1908-1918. The American Historical Review, v. 108, n. 2, p. 337-376, 2003.

WEIGARD, E. The Rugmaker's Daughter, Maud Allan's 1915 silent film. Dance Chronicle, v. 9, n. 2, p. 237-25, 1985.

WHEELWRIGHT, J. The Fatal Lover: Mata Hari and the myth of women in espionage.London: Collins and Brown, 1992.
Recebido: 28/01/2021

Aceito: $23 / 02 / 2021$

Aprovado para publicação: 18/04/2021

Este é um artigo de acesso aberto distribuído sob os termos de uma Licença Creative Commons Atribuição 4.0 Internacional. Disponível em: <http://creativecommons.org/licenses/by/4.0>.

This is an open-access article distributed under the terms of the Creative Commons Attribution License 4.0 International. Available at:<http://creativecommons.org/licenses/by/4.0>.

Ce texte en libre accès est placé sous licence Creative Commons Attribution 4.0 International. Disponible sur:<http://creativecommons.org/licenses/by/4.0>. 